\title{
Coping as a Moderator of The Relation between Recreation Hassles and Hiker Satisfaction
}

\author{
Wei-Li Hung \\ National Taipei University \\ E-Mail: weilihung@mail.ntpu.edu.tw \\ Li-Wen Hsieh \\ National Taipei University \\ E-Mail: hsielee@mail.ntpu.edu.tw
}

\begin{abstract}
The study attempted to explore the relationships among recreation hassles, coping, and hiker satisfaction and to examine the moderating role of coping in the relationship between hassles and satisfaction. Questionnaire surveys were conducted on trails in Yangmingshan National Park in Taiwan in spring 2011. Overall, 316 questionnaires were completed, of which 301 were valid. The results indicated that recreation hassles correlated positively with all coping strategies. Further analysis indicated that the coping behaviors of rationalization significantly moderated the relationship between recreation hassles and hiker satisfaction. The study suggested that an increase in the perceived hassles decreases the satisfaction of hikers. It also indicated that the engagement of the coping strategy of rationalization was likely to decrease the negative effects of hassles on hiker satisfaction. Although a number of studies have discussed a similar argument, relevant empirical works were insufficient. This study clearly confirmed the moderating effect of emotion-focused coping on the relationship between recreation hassles and hiker satisfaction. The study suggests that the Park Headquarters should give the hikers more information on the difficulties and the use of the trails so that the hikers could choose one in accordance with their abilities as well as the frequency of the use of trails.
\end{abstract}

Keywords: Problem-Focused Coping, Emotion-Focused Coping, Moderating Effects 


\section{INTRODUCTION}

Crowding is one of the most important and frequently studied issues in outdoor recreation (Arnberger \& Eder, 2012; Booth, Cessford, McCool, \& Espiner, 2011; Manning \& Valliere, 2001). The increasing numbers of visitors to outdoor recreation areas often create stressful problems, such as traffic jams, noise, or destructive behavior by visitors that negatively influence recreational experiences (Chao \& Wang, 2011; Chhetri, Arrowsmith \& Jackson, 2004; Jacob \& Schreyer, 1980; Lazarus \& Folkman, 1984; Merchan, Diaz-Balteiro \& Solino, 2014). The literature indicates that visitors will employ certain kinds of coping strategies when they confront stress in outdoor recreation (Folkman \& Lazarus, 1980; Schneider \& Budruk, 1999; Schneider \& Hammitt, 1995a). Schuster, Hammitt, and Moore (2003) conceptualized stress as "hassles" based on preceding studies suggesting that daily demands, resources, and constraints operating in recurrent person-environment relationships predict much stress. The term hassles in the present study refers to the definition by Schuster et al. (2003, p.278), "the irritating and frustrating demands or situations that occur during recreation experiences". Previous research has identified two broad categories of copying mechanisms, emotion-focused or cognitive and problem-focused or behavioral (Booth et al., 2011; Miller \& McCool, 2003). The former includes rationalization and product shift, and the latter comprises substitutes (temporal, resource, or activity) and direct action (e.g. complaints to authorities).

The literature suggests that visitor satisfaction may remain relatively high in the case of over-crowded parks because dissatisfied people may no longer visit the park by employing the coping strategy of absolute displacement (Manning, 1999; Manning \& Valliere, 2001). Booth et al. (2011) indicated that the outcomes of behavior coping were examined less due to the difficulty of the measures. The results of empirical research have shown the inconsistency in the outcomes of coping. Chen (2013) suggested that coping behavior could significantly decrease the negative effect of perceived stress on leisure benefits. Schuster, Hammit, and Moore (2006), on the other hand, found that only emotion-focused coping was likely to reduce the level of detraction from visitors' overall satisfaction. Furthermore, Arnberger and Eder (2012) showed that Sunday visitors reported lower satisfaction scores despite their coping efforts. It is still not clear, which types of coping behavior moderate the behavior between perceived hassles and visitor satisfaction. Accordingly, this study intended to explore the moderating role of coping actions in the relation between hassles and visitor satisfaction.

According to the Taiwan Tourism Bureau (2012), hiking is one of the most popular recreation activities in Taiwan. The national parks of the country attract more than 15 million visitors annually and Yangminshan National Park evidently endures 
more recreation stress compared to any other park. Yangmingshan covers a relatively small area and is located very close to the capital, but it accommodates the highest visitor numbers compared to other national parks (Construction and Planning Agency, 2013). Nevertheless, the annual visitor survey of Yangmingshan National Park (2012) shows that the overall visitor satisfaction in the Park is very high, with less than 5 per cent of the respondents indicating dissatisfied experiences. In terms of the three items of psychological experiences, crowding, uncleanliness, and noise, it was found that in Datun recreation area alone, including Erzihping trail (the most popular trail in the Park), nearly one quarter of the respondents reported dissatisfaction with the crowding situation (Yangmingshan National Park Headquarter, 2012). Accordingly, the present research aims to examine the relationships among the three variables: recreation hassles, coping behavior, and the satisfaction of hikers in Yangmingshan National Park.

\section{LITERATURE REVIEW}

\section{Recreation Hassles}

Recreation conflicts have been gaining an increased attention since the 1980s. Jacob and Schreyer (1980) first defined recreation conflict as goal interference, which indicated that one's recreation goal was disturbed by another's behavior. In the 1990s, Schneider and Hammit (1995a) observed that recreationists were likely to evaluate and respond to conflicts similar to their response to other stressful situation in daily life. They built a stress-response model which was applied to other recreational settings by subsequent research (Miller, 1997; Schneider and Hammit, 1995b). Substantially, in the 21 st century, conflict was seen as a hassle (Schuster et al., 2006) and as a constraint (Schneider \& Stanis, 2007). The definitions of conflict have evolved from interpersonal conflict (i.e., goal interference) to social values conflict (i.e., social acceptability) (Schneider et al., 2013).

Conflicts may occur when user groups compete for the same resources; thus, conflicts between recreationists in the same activity are probably seen most frequently in public recreation areas (Arnberger \& Haider, 2007). Vitterso et al. (2004) investigated recreational conflicts between skiers and snowmobiles. Their study showed that skiers found noise from snowmobiles very disturbing. The skiers indicated that encounters with snowmobilers would not only reduce the quality of their recreation experience, but also influence their general beliefs about snowmobiles. Noise is one of the common conflicts reported by recreationists. Merchan et al. (2014), in a study of noise pollution in national parks, found that visitors would be willing to pay an extra fee to support noise-reduction programs. The research of Schneider et al. (2013) also showed that most respondents reported noise ("hearing other users on the trail"). As 
mentioned above, research that is more recent has explored social values conflict. Social values conflict is defined as a conflict resulting from the disagreement among opinions, norms, or values about an activity, and thus it can occur even when there is no direct contact among groups (Vaske et al., 2007). For example, skiers may regard snowmobiles as an inappropriate activity in the natural settings. A number of studies have shown that different activity groups are likely to possess different social values, and this is likely to result in conflict between groups (Tynon \& Gómez, 2012; Van Riper et al., 2012). In addition, conflicts may also occur between recreationists and local residents. Zeppel (2009) identified six types of cross-cultural conflicts among recreational users and among indigenous peoples. This research focuses on conflicts among recreationists.

\section{Coping Strategies}

The literature suggests that visitors will employ some kind of coping behavior or strategies in response to the stress they confront in the outdoor setting (Folkman \& Lazarus, 1980; Schneider \& Budruk, 1999; Shelby, Bregenzer, \& Johnson, 1988). Folkman and Lazarus (1980) defined coping as the efforts one makes to reduce or endure internal or external stress. A number of researchers proposed that coping strategies are either problem- or emotion-focused. Problem-focused strategies indicate the types of behavioral responses, such as direct actions (e.g., telling park personnel about the situation), temporal, resource or activity substitution, or absolute displacement (i.e., leaving the area to find a different location). On the other hand, emotion-focused strategies refer to the types of cognitive responses, such as product shift (i.e., changing the definitions of the experience) or rationalization (i.e., re-evaluating the situation more favorably (Manning \& Valliere, 2001; Miller \& McCool, 2003; Schneider \& Stanis, 2007)

Schneider and Hammit (1995b) indicated that visitors would employ emotional coping strategies if they appraise the stressful situation as being unchangeable. It has also been noted that emotional responses, such as rationalization, are more frequently adopted while the extremes of absolute displacement responses are rare (Manning \& Valliere, 2001). In addition, a number of studies have suggested that recreationists with higher stress intensity are more likely to employ the behavioral coping strategies while those with lower level of stress are likely to use cognitive coping mechanisms (Johnson \& Dawson, 2004; Miller \& McCool, 2003). Schuster et al. (2006) found that stress intensity correlated moderately with problem-focused coping, but there was no significant relationship between intensity and emotion-focused coping. 
Johnson and Dawson (2004) suggested that coping mechanism involves cognitive and behavioral processes that wilderness visitors adopt to enhance their overall recreational satisfaction. The research of Schuster et al. (2006) found that emotion-focused coping had a significant negative influence on level of detraction, whereas the use of problem-focused coping was likely to detract more from the overall recreation experience. The survey of urban forest visitors in Austria undertaken by Arnberger and Eder (2012) showed that workday visitors with temporal substitution reported higher satisfaction scores, while Sunday visitors were less satisfied with the crowding conditions, despite their coping efforts.

The present study aims to explore the moderating role of coping in the relationship between hassles and visitor satisfaction. The hypotheses developed are as follows:

$\mathrm{H}_{1}$ : There is a positive correlation between perceived hassles and coping strategies.

$\mathrm{H}_{2}$ : Coping will have a moderating effect on the relationship between recreation hassles and hiker satisfaction.

\section{METHOD}

\section{Procedure and Participants}

A questionnaire survey was adopted in this study. The target participants were hikers in Yangmingshan National Park. There are many trails in Yangmingshan, with Datun Recreation Area and Lengshuikeng Recreation Area comprising most of the popular hiking trails. The survey was conducted in Datun and Lengshuikeng recreation areas in spring 2011. Overall, 316 questionnaires were completed, of which 301 were valid.

Regarding the demographic profile of the respondents, 155 were males (51.5\%) and 146 were females (48.5\%). The main age group was between 30 and 59, representing $67.1 \%$ of the respondents. Over 70 per cent of the respondents were married, and most of the respondents $(67.1 \%)$ had college or university educations. In terms of occupation, over $20 \%$ of the respondents were in the business industry, and another $15 \%$ of them were in the service sector. The sample in the present study was similar to the sample used in the tourist survey conducted by Yangmingshan National Park Headquarter (2012).

\section{Measures}

The measurement of recreation hassles was in accordance with the research of Schuster et al. (2006). Five indicators (litter, noise, resource damage, crowding, and vehicles) were used to measure hikers' levels of response to hassles on a scale from "none (0)" to "very high (5)". Hikers' satisfaction was measured with reference to the 
concept of the overall satisfaction (Bigné, Sánchez, \& Sánchez, 2001). Five point rating scales $(1=$ very unsatisfactory to $5=$ very satisfactory) were proposed to measure the overall satisfaction of the hikers with the environment and the facilities of the park. The 21-item scale that Miller and McCool (2003) developed was used to measure coping behavior. The scale consisted of 7 factors, which are absolute displacement, temporal substitution, activity substitution, resource substitution, rationalization, product shift, and direct action. All measures were rated on five point scales.

\section{Data Analysis}

SPSS 12.0 was used for the data analysis. The statistics used included descriptive statistics, reliability analysis, correlation analysis, and ANOVA. LISREL 8.52 was used to conduct validity, structural model, and moderating effect analyses. The study examined moderating effects by applying a multiple group analysis (Jaccard \& Wan, 1996). Regarding the moderating variables of coping behaviors, the participants were divided into two groups based on their respective medians. Multiple group SEM analysis was used to identify the existence of moderating effects.

\section{RESULTS}

\section{Descriptive Data}

The survey found that the great majority of the hikers interviewed had experienced some kinds of hassles on their hiking trip, most frequent ones being 'too many people on the trail' (88.7\%) and 'noise from other people' (84.1\%). However, the intensity of these hassles appeared to be relatively low, ranging from 1.19 to 2.03 (see Table 1). Moreover, the results showed that the respondents most frequently employed the coping strategies of direct action $(M=3.17)$ and rationalization $(M=3.16)$. In the light of hikers' satisfaction, the respondents were more satisfied with the recreation environment $(M=4.07)$ than with the recreation facilities $(M=3.84)$.

\section{The Relationship between Recreation Hassles and Coping}

The analysis indicated that recreation hassles correlated positively with all coping strategies, with the Pearson correlation coefficients ranging from .24 to $.33(p<.01)$ (see Table 2). The highest coefficients emerged between the hassles and temporal substitution $(r=.33)$ and resource substitution $(r=.32)$ coping strategies. That is, as hassle levels increased, the respondents were more likely to adopt temporal and resource substitution behaviors. Other coping strategies, such as rationalization and absolute displacement, showed a slightly positive association with the levels of hassles ( $r=.24$ and $r=.25$, respectively). Therefore, hypothesis 1 was supported. 
Table 1 Means, factor scores and reliabilities for measurement model

\begin{tabular}{|c|c|c|c|c|c|c|}
\hline Factor/item & Mean & SD & $\lambda$ & $\alpha$ & $\mathbf{C R}$ & AVE \\
\hline Hassle & & & & .86 & .87 & .56 \\
\hline Litter & 1.19 & 1.03 & .73 & & & \\
\hline Noise from other people & 1.68 & 1.13 & .77 & & & \\
\hline Damage to the resource (plants, trails) & 1.32 & 0.99 & .86 & & & \\
\hline Too many people on the trails & 2.03 & 1.21 & .68 & & & \\
\hline Vehicles near the area & 1.84 & 1.32 & .70 & & & \\
\hline Satisfaction & & & & .79 & .80 & .66 \\
\hline S1 & 4.07 & 0.62 & .84 & & & \\
\hline $\mathrm{S} 2$ & 3.84 & 0.68 & .79 & & & \\
\hline Coping Behavior & & & & & & \\
\hline Absolute displacement (AD) & 1.72 & 0.71 & & .87 & .87 & .69 \\
\hline AD1 & 1.79 & 0.84 & .89 & & & \\
\hline AD2 & 1.63 & 0.73 & .80 & & & \\
\hline AD3 & 1.73 & 0.81 & .80 & & & \\
\hline Temporal substitution (TS) & 2.87 & 1.05 & & .85 & .85 & .65 \\
\hline TS1 & 2.60 & 1.15 & .82 & & & \\
\hline TS2 & 2.93 & 1.22 & .87 & & & \\
\hline TS3 & 3.10 & 1.24 & .73 & & & \\
\hline Activity substitution (AS) & 2.36 & 0.95 & & .85 & .86 & .68 \\
\hline AS1 & 2.59 & 1.12 & .89 & & & \\
\hline AS2 & 2.48 & 1.11 & .92 & & & \\
\hline AS3 & 2.00 & 1.01 & .63 & & & \\
\hline Resource substitution (RS) & 2.87 & 1.09 & & .89 & .90 & .74 \\
\hline RS1 & 2.84 & 1.22 & .88 & & & \\
\hline RS2 & 2.70 & 1.17 & .87 & & & \\
\hline RS3 & 3.04 & 1.21 & .83 & & & \\
\hline Rationalization & 3.16 & 0.90 & & .75 & .76 & .51 \\
\hline R1 & 3.32 & 1.11 & .76 & & & \\
\hline R2 & 3.30 & 1.12 & .71 & & & \\
\hline R3 & 2.84 & 1.06 & .68 & & & \\
\hline Product shift (PS) & 2.89 & 0.99 & & .86 & .85 & .66 \\
\hline PS1 & 3.03 & 1.11 & .83 & & & \\
\hline PS2 & 2.79 & 1.13 & .80 & & & \\
\hline PS3 & 2.88 & 1.14 & .80 & & & \\
\hline Direct action (DA) & 3.17 & 0.93 & & .86 & .88 & .70 \\
\hline DA1 & 3.19 & 1.08 & .69 & & & \\
\hline DA2 & 3.07 & 1.02 & .91 & & & \\
\hline DA3 & 3.24 & 1.06 & .90 & & & \\
\hline
\end{tabular}

$\mathrm{CR}=$ construct reliability; $\mathrm{AVE}=$ average variance extracted

Table 2 Inter-correlations between the variables 


\begin{tabular}{|c|c|c|c|c|c|c|c|c|c|c|}
\hline & Hasl & $\mathrm{AD}$ & $\mathrm{TS}$ & AS & $\mathrm{RS}$ & $\mathrm{R}$ & PS & DA & S1 & $\mathrm{S} 2$ \\
\hline Hasl & 1 & & & & & & & & & \\
\hline $\mathrm{AD}$ & $.252 * *$ & 1 & & & & & & & & \\
\hline TS & $.328^{* *}$ & $.439 * *$ & 1 & & & & & & & \\
\hline AS & $.275^{* *}$ & $.508^{* *}$ & $.640^{* *}$ & 1 & & & & & & \\
\hline RS & $.320^{* *}$ & $.325^{* *}$ & $.705^{* *}$ & $.693^{* *}$ & 1 & & & & & \\
\hline $\mathrm{R}$ & $.237^{* *}$ & $.217^{* *}$ & $.459 * *$ & $.428 * *$ & $.537 * *$ & 1 & & & & \\
\hline PS & $.284^{* *}$ & $.174^{* *}$ & $.440^{* *}$ & $.341^{* *}$ & $.464^{* *}$ & $.605^{* *}$ & 1 & & & \\
\hline DA & $.248^{* *}$ & $.326^{* *}$ & $.517 * *$ & $.501 * *$ & $.598^{* *}$ & $.590 * *$ & $.460 * *$ & 1 & & \\
\hline $\mathrm{S} 1$ & $-.385^{* *}$ & $-.306^{* *}$ & $-.287^{* *}$ & $-.280^{* *}$ & $-.277^{* *}$ & $-.172 * *$ & $-.249^{* *}$ & $-.251^{* *}$ & 1 & \\
\hline $\mathrm{S} 2$ & $-.369^{* *}$ & $-.237^{* *}$ & $-.243 * *$ & $-.297^{* *}$ & $-.293^{* *}$ & $-.140 *$ & $-.177^{* *}$ & $-.291 * *$ & $.660^{* *}$ & 1 \\
\hline
\end{tabular}

\section{Measurement model}

Table 1 shows the factor loadings, internal consistency reliabilities, construct reliabilities (CR), and average variance extracted (AVE) for three scales. Two confirmatory factor analyses (CFA) were conducted. The results showed that the measurement models for recreational hassle and satisfaction fit the data well $\left(\chi 2_{(13)}=29.27, \chi 2 / d f=2.25, \mathrm{RMSEA}=.063, \mathrm{NFI}=.98, \mathrm{CFI}=.99, \mathrm{NNFI}=.98\right)$. The 7 -factor coping behavior model was also found fit the data with acceptable fit indices $\left(\chi 2_{(168)}=396.84, \chi 2 / d f=2.36\right.$, RMSEA $\left.=.07, \mathrm{NFI}=.95, \mathrm{CFI}=.96, \mathrm{NNFI}=.96\right)$. Convergent validity was evident since all factor loadings were significant, $p<.05$. The internal consistency reliability of the scales was high, with Cronbach's alpha scores ranging from .75 to .89 and the CR scores from .76 to .90 . The AVE scores ranged from .51 to .74 , also indicating good construct reliabilities.

\section{Baseline Structural Model}

A baseline structural model with path relationship between recreational hassle and hiker satisfaction was examined using a structural equation modeling method. The fit statistics indicated that the baseline model fits the data well $\left(\chi_{(13)}^{2}=29.68, \chi^{2} / d f=2.28\right.$, RMSEA $=.064, \mathrm{NFI}=.98, \mathrm{CFI}=.99, \mathrm{NNFI}=.98$ ). Recreational hassle explained $25 \%$ of variance in hiker satisfaction and path coefficient was significant $(\gamma=-.50, p<.05)$.

\section{Moderating Effects}

The study examined moderating effects by applying multiple group analyses on the baseline structural model. The participants were divided into two subgroups (low score group and high score group) based on the respective median of seven coping 
behavior variables. Invariance tests of the structural model between two subgroups were performed. The results showed that, with the exception of the coping behavior of activity substitution, the participant subgroups with higher scores of coping behaviors tended to have lower path coefficients (Table 3). However, as shown in Figure 1, only the coping behaviors of rationalization significantly moderated the relationship between recreation hassles and hiker satisfaction $(\Delta \chi 2(1)=4.03, \mathrm{p}<.05$, Table 2$)$. Therefore, hypothesis 2 was partially supported.

\section{DISCUSSIONS AND IMPLICATIONS}

The results of the study showed that recreation hassles were positively correlated with all coping behaviors factors. This is different from the findings of previous research. The study of Miller and McCool (2003) showed that recreation hassles correlated positively with the coping behaviors of absolute displacement and direct action, but they correlated negatively with cognitive adjustment strategies. The survey conducted by Schuster et al. (2006) also found a positive correlation between hassles and problem-focused coping, but the results showed no significant relationship between hassle intensity and emotion-focused coping.

Table 3 Moderating effects of coping behaviors on baseline model

\begin{tabular}{|c|c|c|c|c|c|c|c|}
\hline \multirow[b]{2}{*}{ Moderator } & \multicolumn{2}{|c|}{$\begin{array}{c}\text { Low Score } \\
\text { Group }\end{array}$} & \multicolumn{2}{|c|}{$\begin{array}{c}\text { High Score } \\
\text { Group }\end{array}$} & \multirow{2}{*}{$\begin{array}{c}\text { Group } \\
\text { Unequal } \\
\chi^{2}(\mathrm{df})\end{array}$} & \multirow{2}{*}{$\begin{array}{l}\text { Group } \\
\text { Equal } \\
\chi^{2}(\mathrm{df})\end{array}$} & \multirow{2}{*}{$\begin{array}{l}\text { Difference } \\
\Delta \chi^{2}(\Delta \mathrm{df})\end{array}$} \\
\hline & $\mathrm{n}$ & $r$ & $\mathrm{n}$ & $r$ & & & \\
\hline $\begin{array}{l}\text { Absolute } \\
\text { displacement }\end{array}$ & 156 & -.50 & 138 & -.40 & $39.71(26)$ & $40.12(27)$ & $0.41(1)$ \\
\hline $\begin{array}{l}\text { Temporal } \\
\text { substitution }\end{array}$ & 132 & -.55 & 162 & -.40 & $48.50(26)$ & $49.43(27)$ & $0.93(1)$ \\
\hline $\begin{array}{l}\text { Activity } \\
\text { substitution }\end{array}$ & 159 & -.42 & 135 & -.49 & $45.58(26)$ & $45.79(27)$ & $0.21(1)$ \\
\hline $\begin{array}{l}\text { Resource } \\
\text { substitution }\end{array}$ & 131 & -.58 & 163 & -.38 & $45.83(26)$ & 47.55 (27) & $1.72(1)$ \\
\hline Rationalization & 123 & -.66 & 171 & -.37 & $40.27(26)$ & $44.30(27)$ & $4.03^{*}(1)$ \\
\hline Product shift & 123 & -.59 & 171 & -.39 & $50.34(26)$ & $52.11(27)$ & $1.77(1)$ \\
\hline Direct action & 129 & -.62 & 165 & -.38 & $51.25(26)$ & $53.81(27)$ & $2.56(1)$ \\
\hline
\end{tabular}




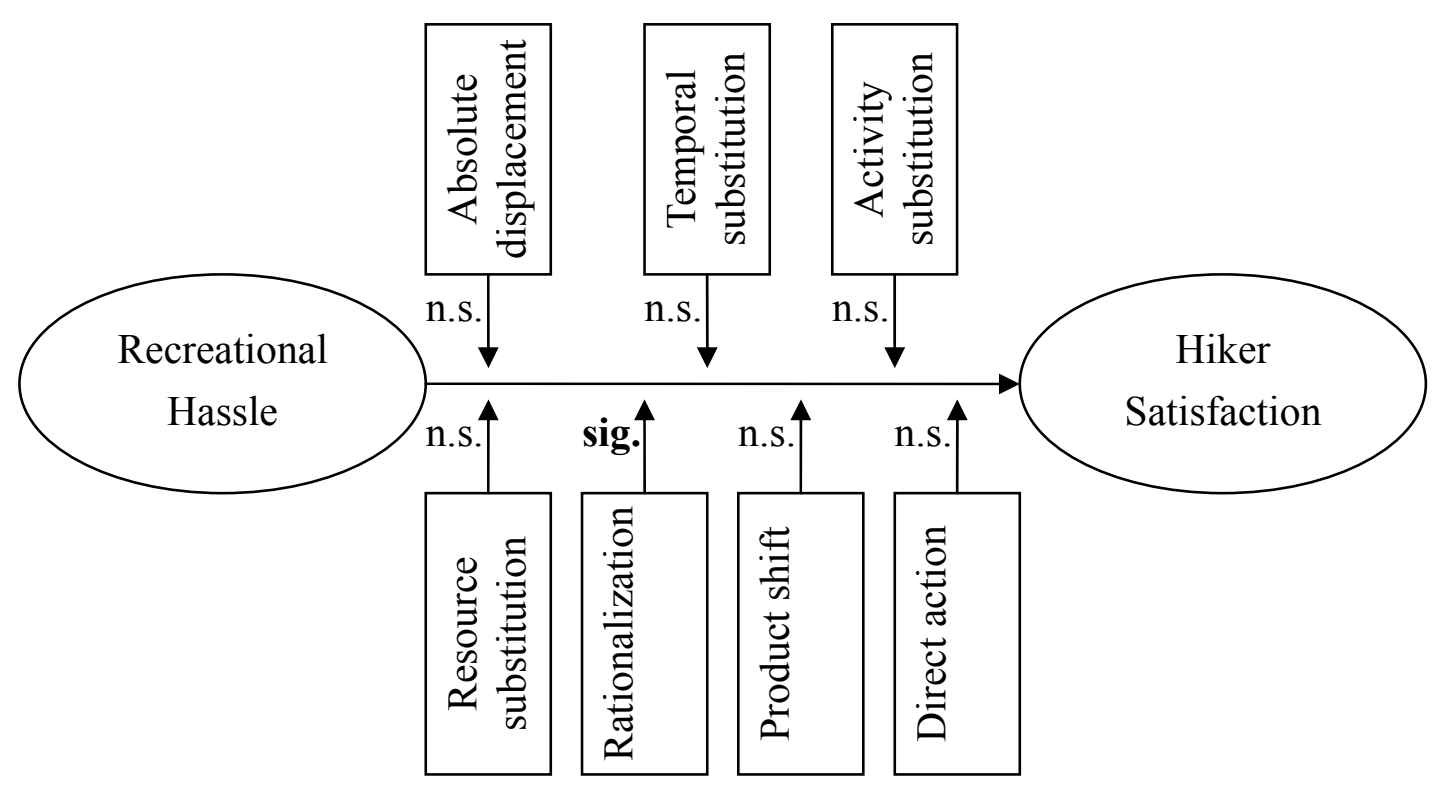

Figure 1 Moderating effects of coping behaviors on baseline model

This study indicated that only the cognitive coping behavior - rationalization moderated the relation between recreation hassles and hiker satisfaction. It was found that rationalization coping was likely to decrease the negative effects of recreation hassles on the satisfaction of hikers. Chen (2013) indicated that coping behaviors significantly moderated the relationship between recreation stress and leisure benefits. However, his study did not identify individual effects among the coping behaviors. Schuster et al. (2006) found that the use of problem-focused coping was likely to cause more detraction from the overall recreation experience while the negative influence of emotion-focused coping on detraction implied that emotion-focused coping might have a moderating effect on the relationship between hassles and satisfaction with recreation experience. The findings of the present study support their study.

The present study attempted to explore the relationships among recreation hassles, coping behavior, and hiker satisfaction. The results showed that as the perceived hassles increased, the satisfaction of hikers was likely to decrease. Further analysis indicated that the engagement of the coping strategy of rationalization was likely to decrease the negative effects of hassles on hiker satisfaction. Although similar argument has been discussed in a number of studies, empirical work has been insufficient. This study confirms the moderating effect of cognitive coping on the relationship between recreation hassles and hiker satisfaction.

The current study found that the respondents were least likely to adopt absolute displacement as a coping strategy while they were most likely to utilize rationalization and direct action. While most recreational areas in northern Taiwan are crowded, 
Yangmingshan National Park is superior in terms of its resources and facilities. Most hikers are believed to be repeat visitors; therefore, they should be aware of the situation of crowding. The study also suggests that as the perceived hassles increase, the hikers are more likely to employ temporal and resource substitutions. Erzihping is the most popular trail in Yangmingshan because of its wide and flat path, and it is the only trail designated for handicapped people. The study suggests that the Park Headquarter should give hikers more information about the difficulty and the use level of trails, allowing them to choose one in accordance with their ability as well as the density of the use of trails.

The results showed that the perceived hassles were very low. This is probably because the hiking environment and facilities in Yangmingshan National Park are relatively satisfactory, as discussed above. The small variations in perceived hassles might influence the analysis of the relationships among the variables. As a result, it is recommended that future research include various sites. Moreover, since the studies reported inconsistent findings, there is a need for more empirical research in the future.

\section{REFERENCES}

Arnberger, A. and Eder, R. (2012). Exploring coping behaviours of Sunday and workday visitors due to dense use conditions in an urban forest. Urban Forestry \& Urban Greening 11, 439-449. http://dx.doi.org/10.1016/j.ufug.2012.08.002

Arnberger, A. and Haider, W. (2007). A comparison of global and actual measures of perceived crowding of urban forest visitors. Journal of Leisure Research, 39(4), 668-685.

Bigné, J. E., Sánchez, M. I. and Sánchez, J. (2001). Tourism image, evaluation variables and after purchase behaviour: inter-relationship. Tourism Management, 22(6), 607-616. http://dx.doi.org/10.1016/S0261-5177(01)00035-8

Booth, K. L., Cessford, G. R., McCool, S. F., and Espiner, S. R. (2011). Exploring visitor experiences, crowding perceptions and coping strategies on the Milford Track, New Zealand. Department of Conservation, The Terrace Wellington 6143, New Zealand.

Chao, C. L. and Wang, I. T. (2011). The study of the recreation conflicts and coping behaviors on mountain walkers. Journal of Island Tourism Research, 4(1), 55-78.

Chen, K. K. (2013). Perceived stress of recreation and leisure benefits - the moderating role of coping behaviors. Journal of Leisure, Tourism, Sport, \& Health, 3(2), 87-108. 
Chhetri, P., Arrowsmith, C. and Jackson, M. (2004). Determining hiking experiences in nature-based tourist destinations. Tourism Management, 25(1), 31-43. http://dx.doi.org/10.1016/S0261-5177(03)00057-8

Construction and Planning Agency (2013). The statistics of the national parks of Taiwan. Retrieved August 19, 2013, from http://np.cpami.gov.tw/youth/index.php?option=com_statistics\&view=statistics\& $\underline{\text { Itemid }=182}$

Folkman, S. and Lazarus, R. S. (1980). An analysis of coping in a middle-aged community sample. Journal of Health and Social Behavior, 21, 219-239. http://dx.doi.org/10.2307/2136617

Jaccard, J. and Wan, C. K. (1996). LISREL analyses of interaction effects in multiple regression. Newbury Park, CA: Sage.

Jacob, G. R., and Schreyer, R. (1980). Conflict in outdoor recreation: A theoretical perspective. Journal of Leisure Research, 12(4), 368-380.

Johnson, A. K., and Dawson, C. P. (2004). An exploratory study of the complexities of behavior in Adirondack wilderness. Leisure Sciences, 26, 281-293. http://dx.doi.org/10.1080/01490400490461963

Lazarus, R. S and Folkman, S. (1984). Stress, appraisal, and coping. New York: Springer Publishing Company.

Manning, R. E. (1999). Studies in outdoor recreation: Search and research for satisfaction. Corvallis, OR: Oregon State University Press.

Manning, R. E., and Valliere, W. A. (2001). Coping in outdoor recreation: Causes and consequences of crowding among community residents. Journal of Leisure Research, 33(4), 410-426.

Merchan, C. I., Diaz-Balteiro, L., and Solino, M. (2014). Noise pollution in national parks: Soundscape and economic valuation. Landscape and Urban Planning, 123(1), 1-9.

Miller, T. A., and McCool, S. F. (2003). Coping with stress in outdoor recreational settings: An application of transactional stress theory. Leisure Sciences, 25, 257-275. http://dx.doi.org/10.1080/01490400306562

Schneider, I. E., and Hammitt, W. E. (1995a). Visitor response to outdoor recreation conflict: A conceptual approach. Leisure sciences, 17, 223-234. http://dx.doi.org/10.1080/01490409509513258

Schneider, I. E. and Hammit, W. E. (1995b). Visitor responses to on-site recreation conflict. Journal of Applied Recreation Research, 20(4), 249-268. 
Schneider, I. E., and Budruk, M. (1999). Displacement as a response to the federal recreation fee program. Journal of Park and Recreation Administration, 17(3), 76-84.

Schneider, I. E., and Stanis, S. W. (2007). Coping: An alternative conceptualization for constraint negotiation and accommodation. Leisure Sciences, 29(4), 391-401. http://dx.doi.org/10.1080/01490400701394915

Schneider, I. E., Earing, J., and Martinson, K. (2013). Revealing motivations for and conflicts associated with recreational horseback trail riding. Journal of Forestry, 111(4): 282-286. http://dx.doi.org/10.5849/jof.12-056

Schuster, R. M., Hammitt, W. E., and Moore, D. (2003). A theoretical model to measure the appraisal and coping response to hassles in outdoor recreation settings. Leisure Sciences, 25, 277-299. http://dx.doi.org/10.1080/01490400306568

Schuster, R. M., Hammitt, W. E., and Moore, D. (2006). Stress appraisal and coping response to hassles experienced in outdoor recreation settings. Leisure Sciences, 28, 97-113. http://dx.doi.org/10.1080/01490400500483919

Shelby, B., Bregenzer, N. S., and Johnson, R. (1988). Displacement and product shift: Empirical evidence from Oregon Rivers. Journal of Leisure Research, 20(4), 274-288.

Tourism Bureau (2012). 2011 Survey of Travel by R.O.C. Citizens. Tourism Bureau, Ministry of Transportation and Communications.

Tynon, J. F. and Gómez, E. (2012). Interpersonal and social values conflict among coastal recreation activity groups in Hawaii. Journal of Leisure Research, 44(4), 531-543.

Van Riper, C. J., Kyle, G. T., Sutton, S. G., Barnes, M., and Sherrouse, B. C. (2012). Mapping outdoor recreationists' perceived social values for ecosystem services at Hinchinbrook Island National Park. Australia. Applied Geography, 35(1-2), 164-173. http://dx.doi.org/10.1016/j.apgeog.2012.06.008

Vaske, J. J., Needham, M. D., and Cline, R. C. (2007). Clarifying interpersonal and social values conflict among recreationists. Journal of Leisure Research, 39(1), 182-195.

Vitterso, J., Chipeniuk, R., Skar, M., and Vistad, O. (2004). Recreational conflict is affective: The case of cross-country skiers and snowmobiles. Leisure Sciences, 26(3), 227-243. http://dx.doi.org/10.1080/01490400490461378

Yangmingshan National Park Headquarter (2012). The survey of visitor satisfaction of Yangmingshan National Park. Retrieved August 19, 2013, from http://www.ymsnp.gov.tw/index.php?option=com_govopen\&view $=$ stats $\& g p=0 \&$ 
Itemid=456http://www.ymsnp.gov.tw/index.php?option=com_govopen\&view=st ats $\& g p=0 \&$ Itemid $=456$

Zeppel, H. (2009). Managing cultural values in sustainable tourism: conflicts in protected areas. Tourism and Hospitality Research, 10(2), 93-104. http://dx.doi.org/10.1057/thr.2009.28 